\title{
Estudo da evasão dos estudantes de Licenciatura e Bacharelado em Física: uma análise à luz da Teoria do Sistema de Ensino de Bourdieu ${ }^{+}$
}

\author{
João Fernandes ${ }^{1}$ \\ Universidade de São Paulo \\ São Paulo - SP \\ Michele Hidemi Ueno Guimarães ${ }^{1}$ \\ Universidade Federal de Ouro Preto \\ Ouro Preto - MG \\ André Robert ${ }^{1}$ \\ Université Lumière Lyon 2 - França \\ Marinez Meneghello Passos ${ }^{1}$ \\ Universidade Estadual de Londrina \\ Londrina - SP
}

\section{Resumo}

A evasão e a retenção são problemas que circundam os cursos de Física por todo o Brasil. Neste artigo, apresentamos os resultados de uma investigação, que se propôs a levantar alguns dos motivos relacionados a esses fenômenos. Para isso, foram feitas entrevistas com estudantes e os professores dos cursos de Licenciatura e Bacharelado em Física da Universidade Federal de Ouro Preto. Para o estudo dessa problemática assumimos a Teoria do Sistema de Ensino de Bourdieu, evidenciando as diversas relações de dominância existentes nos cursos, o que contribui para que a evasão e a retenção nesta Universidade analisada sejam altíssimas. Entre as conclusões a que chegamos, após os procedimentos analíticos do corpus investigativo, ou seja, dos relatos coletados, destacamos: para os estudantes esses motivos concentram-se nas relações pessoais "complicadas" com os professores e na rotina "acelerada" nas repúblicas em que residem; para os professores, o principal fator está

\footnotetext{
${ }^{+}$Study of the evasion of undergraduate students of the Licentiateship and Bachelor in Physics: an analysis in light of Bourdieu's Theory of the Education System

* Recebido: agosto de 2019. Aceito: fevereiro de 2020.

${ }^{1}$ E-mails: joaof@if.usp.br; micheleueno@usp.br; andre.robert@univ-lyon2.fr; marinezmp@sercomtel.com.br
} 
relacionado ao uso do curso de Física como um "trampolim" para outros cursos, principalmente, Engenharias.

Palavras-chave: Evasão; Licenciatura e Bacharelado em Física; Relações de Dominância.

\begin{abstract}
Evasion and retention are problems surrounding physics courses throughout Brazil. In this article, we present the results of an investigation that proposed to raise some of the reasons related to these phenomena. For this, interviews were made with students and teachers of the Licentiateship and Bachelor of Physics courses of Universidade Federal de Ouro Preto. For the study of this problem we assume Bourdieu's Theory of the Education System, highlighting the various relationships of dominance that exist in the courses, which contributes to the high evasion and retention in this analysed University. Among the conclusions reached, after the analytical procedures of the investigative corpus, that is, the collected reports, we highlight: for the students these motives focus on the "complicated" personal relations with the teachers and the "accelerated" routine in the republics where they reside; For teachers, the main factor is related to the use of the Physics course as a "trampoline" for other courses, mainly Engineering.
\end{abstract}

Keywords: Evasion; Licentiateship and Bachelor of Physics; Dominancy Relationships.

\title{
I. Introdução
}

A grande evasão e retenção dos cursos de Física é uma realidade em diversos locais do País. O discurso que circula entre alunos e professores é o de que o curso apresenta muitas dificuldades e que somente um estudante com uma habilidade superior poderia concluir o curso com êxito.

Dentre os autores que realizaram pesquisas sobre o assunto, destacamos Barroso e Falcão (2004) e Soares (2014), que apresentam um panorama que relaciona a alta taxa de reprovações nas disciplinas iniciais do curso à elevada taxa de evasão; Silva Filho et al. (2007), num estudo quantitativo revelou as taxas de evasão nos cursos de Física em 2005; Almeida e Schimiguel (2011) e Rabelo (2012), relacionam a evasão às condições de trabalho do Físico em contraste a outras áreas, aumentando assim o número de transferências internas; Lima Junior, Ostermann e Rezende (2012) relatam que a posição na camada de classes dos estudan- 
tes não possui uma relevância direta na evasão ou diplomação dos alunos, mas na sua retenção; Silva e Franco (2014) levantaram questões que dialogam com o fato de a formação dos alunos no Ensino Médio não fornecer suportes matemáticos suficientes para os desafios do curso; Ferreira (2017) destaca dois dos fatores já apresentados: dificuldade nas disciplinas iniciais e vontade de fazer outro curso como os principais fatores da evasão em seu campus.

Considerando essas constatações que perpassam mais de uma década, dedicamo-nos, então, ao desenvolvimento desta pesquisa, que objetivou compreender os motivos pelos quais os estudantes evadem ou são retidos nas habilitações de Bacharelado e Licenciatura em Física, da Universidade Federal de Ouro Preto (UFOP). Para isso, foram realizadas entrevistas com alunos e professores da Instituição, com o intuito de conhecer suas percepções sobre este fato.

Para este desenvolvimento estamos assumindo a evasão como a interrupção dos estudos, com possibilidade de retorno, ou seja, um aluno evadido é aquele que deixa a escola, mas que tem possibilidade de retorno à mesma (ABRAMOVAY; CASTRO, 2003; BAGGI; LOPES, 2011). Diferentemente do abandono escolar, quando o aluno deixa a escola sem perspectivas de retorno. Por retenção, compreendemos as situações em que o estudante ultrapassa o tempo ideal do curso, ou seja, chega a se formar, todavia com um tempo alongado.

Devido à maneira como o Ministério da Educação e Cultura (MEC) tem calculado a taxa de conclusão média dos cursos de graduação, a evasão e a retenção têm se tornado assuntos de extrema importância, pois implicam em um investimento cada vez menor por parte do governo federal, que leva em consideração estes índices.

Estas constatações explanadas rapidamente nos parágrafos anteriores conduziramnos a duas indagações: O que faz os alunos desistirem do curso de Licenciatura e Bacharelado em Física? Além do jargão presente de que "Física é um curso difícil", existem outros motivos que favorecem a evasão e a retenção na Universidade em que realizamos a pesquisa?

Para realizar as análises dos dados coletados, fundamentamo-nos em Pierre Bourdieu, acerca da Teoria do Sistema de Ensino. De acordo com o autor, a escola é um mecanismo de reprodução do sistema de classes, no qual a classe dominante impõe os seus arbítrios culturais sobre a classe dominada. Isso vem ao encontro de nossas primeiras percepções sobre o fenômeno em questão: de um lado, na visão dos alunos, o problema estaria relacionado aos professores, na forma como cada um deles conduz as aulas, nas relações pessoais marcadas por antipatia e intolerância, na incompreensão associada às dificuldades de aprendizagem dos conteúdos por parte dos alunos; em contraposição, sob a perspectiva dos professores, o problema estaria nos alunos, que não se interessam em continuar o curso e, muitas vezes, apenas o utilizam como "trampolim", para os cursos de Engenharia, não demonstram suficiente interesse pelo curso, colocando outras prioridades antes dos estudos.

A fim de elucidar todo esse processo investigativo e as escolhas teóricas e metodológicas realizadas para este desenvolvimento, estruturamos este artigo trazendo algumas informações descritivas do contexto investigado, com a intenção de elucidar determinadas conside- 
rações conclusivas, o referencial teórico que sustentou nossas análises das informações, os encaminhamentos metodológicos, a apresentação dos dados, diversas das análises realizadas e as evidências finais.

\section{Informações descritivas}

Antes de iniciarmos as descrições da Universidade e dos cursos, é necessário contextualizar a pesquisa em relação à cidade em que a instituição se encontra. Ouro Preto - MG - é uma cidade histórica universitária, e que devido a isso, possui uma tradição de repúblicas (casas compartilhadas entre alunos). Estas repúblicas são classificadas em três tipos: federais, particulares e apartamentos.

O primeiro se refere às casas cedidas pela UFOP, onde os alunos fazem o gerenciamento das pessoas e costumes internos, como decidir moradores, deveres domésticos etc. A instituição é responsável por pagar as contas de água, eletricidade e é isenta de aluguel, uma vez que são imóveis próprios. O segundo tipo, são similares às federais, porém os moradores são responsáveis, também, pelo pagamento de todas as contas da casa, uma vez que o imóvel é alugado de terceiros. Por fim, existem os chamados apartamentos, que são também repúblicas, mas que não possuem status de tal. Seus moradores não têm o costume de fazer grandes festas e de se envolver, como entidade republicana, em outras festas.

Outro ponto a salientar é a cultura de festas da cidade. Em 2012, foi feito um estudo que constatou que a UFOP é a universidade que consome mais álcool do Brasil (HOLANDA, 2012). Entendemos que esta cultura festiva é um dos fatores que contribui para aumentar o índice de evasão dos cursos de Física, como discutiremos mais à frente.

Em função do que pretendíamos investigar reunimos alguns dados, acerca do número de alunos matriculados, egressos, diplomados, evadidos, com a matrícula trancada, além da quantidade de professores efetivos e substitutos do Departamento. Todos estes dados foram fornecidos pela Sessão de Ensino do Instituto de Ciências Exatas e Biológicas da UFOP.

Nesta Instituição, há duas habilitações: Licenciatura, com uma oferta de 10 vagas anuais e o Bacharelado, com 25 vagas anuais. Ambas têm a entrada no curso no primeiro semestre letivo, porém as duas habilitações não foram criadas simultaneamente.

O Bacharelado foi criado em 1999, e conta, hoje, com duas ênfases: Física de Materiais e Física Geral. Já a Licenciatura foi criada apenas em 2012 e não conta com nenhuma ênfase. Durante os dois primeiros anos, após a criação, a Licenciatura oferecia apenas 5 vagas anuais. A partir de 2014, e até o momento, o curso aumentou este número para 10 vagas. $\mathrm{Na}$ Tabela 1 e na Tabela 2, dispomos a quantidade de alunos matriculados, diplomados, evadidos e de alunos que trancaram suas matrículas na Licenciatura e no Bacharelado, respectivamente, até o ano de 2017. 
Tabela 1 - Panorama geral sobre o curso de Licenciatura em Física no período de 2012 a 2017.

\begin{tabular}{|c|c|c|c|}
\hline Alunos Licenciatura & Homens & Mulheres & Total \\
\hline Matriculados & 15 & 5 & 20 \\
\hline Diplomados & 0 & 0 & 0 \\
\hline Evadidos & 19 & 6 & 25 \\
\hline Trancados & 0 & 1 & 1 \\
\hline Total & 34 & 12 & 46 \\
\hline
\end{tabular}

Fonte: os autores.

A partir da tabela anterior, é possível inferir que a Licenciatura não havia formado qualquer estudante até 2017, destacamos complementarmente que o primeiro aluno concluiu o curso em 2018. É fato que nos seis anos de existência da Licenciatura, um número de 10 alunos poderia ter finalizado o curso, o que infelizmente não ocorreu. A porcentagem de evasão, no período analisado, foi de $54,35 \%$ e existia apenas um aluno com sua matrícula trancada no curso, o que representa 5,00\% do total de matriculados, lembrando sempre que estas quantidades podem variar, de acordo com a atualização do sistema.

Podemos perceber, também, que o número de mulheres é significativamente inferior ao número de homens. De um total de 46 alunos que ingressaram no curso, apenas 12 deles eram mulheres, o que representava $26,08 \%$ do total, enquanto os homens representavam $73,92 \%$. Este fato não acontece apenas na Licenciatura, mas isto também é recorrente em outras habilitações e em outras Instituições, conforme indicam Ueno (2004) e Ueno-Guimarães (2014).

A Tabela 2, disponibilizada a seguir, descreve as informações a respeito do Bacharelado em um período mais amplo, pois o curso data de 1999.

Tabela 2 - Panorama geral sobre o curso de Bacharelado em Física no período de 1999 a 2017.

\begin{tabular}{|c|c|c|c|}
\hline Alunos Bacharelado & Homens & Mulheres & Total \\
\hline Matriculados & 31 & 8 & 39 \\
\hline Diplomados & 70 & 38 & 108 \\
\hline Evadidos & 234 & 71 & 305 \\
\hline Trancados & 2 & 1 & 3 \\
\hline Total & 337 & 118 & 455 \\
\hline
\end{tabular}

Fonte: os autores.

Realizando uma leitura similar à da Tabela 1, podemos constatar que dos 455 ingressantes no curso de Bacharelado, somente 108 concluíram o curso, o que representa 23,74\% dos ingressantes, mantendo-se a realidade de poucos alunos diplomados. Com relação à por- 
centagem de evasão do curso, ela é um pouco maior do que a da Licenciatura, em torno de $67,03 \%$ e existiam 3 alunos com a matrícula trancada, o que representava 7,69\% do total de alunos matriculados.

Complementando a discussão levantada por Ueno (2004), podemos ver também no curso de Bacharelado, que o número de mulheres é significativamente menor do que o de homens, apenas 118 do total eram mulheres, o que representava 25,93\%.

Quanto às informações sobre os professores dos cursos, elas foram acessadas diretamente no sítio da Universidade no mês de janeiro de 2018 e organizadas na Tabela 3, destacando os efetivos e os substitutos (assim denominados na Instituição).

Tabela 3 - Número de docentes, efetivos e substitutos.

\begin{tabular}{|l|c|c|c|}
\hline Professores & Homens & Mulheres & Total \\
\hline Efetivos & 24 & 6 & 30 \\
\hline Substitutos & 3 & 1 & 4 \\
\hline Total & 27 & 7 & 34 \\
\hline
\end{tabular}

Fonte: os autores

Esses números são aproximados, uma vez que o Departamento está com constante troca de professores. O corpo docente conta com $88,24 \%$ dos seus membros como efetivos, logo $11,76 \%$ deles são substitutos.

Da mesma forma que os alunos, podemos perceber que o número de mulheres é significativamente inferior ao número de homens, no corpo docente do Departamento. Tanto em termos de professores efetivos quanto substitutos, o número de homens é superior ao de mulheres. De um total de 34 docentes, o número de mulheres é apenas 7 , o que representa $20,59 \%$.

Como já indicado, após esta descrição de algumas informações sobre os cursos investigados, elaboramos esclarecimentos a respeito do aporte teórico que contribui com as análises realizadas das informações coletadas.

\section{Encaminhamentos teóricos}

Tendo em vista a natureza do objeto de investigação, o uso de um referencial teórico da Sociologia se faz necessário. Evasão e retenção dos estudantes são aspectos que levam em consideração características que vão além das de cada indivíduo isoladamente, mas também com a forma com que cada um se relaciona dentro dos diversos grupos. Assim, a Sociologia nos fornece instrumentos para investigar as características de cada um desses grupos, bem como as possíveis causas do elevado número de evasão e retenção dos cursos de Licenciatura e de Bacharelado em Física da UFOP. 
Entre outros motivos, escolhemos Bourdieu (2004) como referencial teórico. De maneira inédita, Bourdieu (2004) tenta relacionar essas duas perspectivas, em um trabalho classificado por ele como contructivist structuralism ou structuralist constructivism. Para o autor, estruturalismo ou estruturalista está relacionado com a "existência de estruturas objetivas, independentes da consciência e vontade dos seus agentes, as quais são capazes de orientar ou coagir suas práticas e representações" (2004, p. 149). Com relação ao construtivismo ou construtivista, ele afirma existir uma dialética: de um lado, uma construção social, permeada pelos pensamentos e ações, que constitui o que ele denomina de habitus, e do outro, as estruturas sociais, mais comumente conhecidas como estruturas de classe.

De um lado, as estruturas objetivas que o sociólogo constrói no momento objetivista, descartando as representações subjetivistas dos agentes, são o fundamento das representações subjetivas e constituem as coações estruturais que pesam nas interações; mas, de outro lado, essas representações também devem ser retidas, sobretudo se quisermos explicar as lutas cotidianas, individuais ou coletivas, que visam a transformar ou conservar essas estruturas. (BOURDIEU, 2004, p. 152).

Para Bourdieu (2004), o indivíduo não constrói sua personalidade sozinho. É juntamente com as influências do meio em que ele está incluído que a moldam e constroem. Para ele, o indivíduo é construído em seus mínimos detalhes, desde suas vestimentas, vocabulários, até a sua postura perante a escolha e perspectivas sobre o futuro profissional. Mas a sociedade não exerce um papel inflexível nessa moldagem. $\mathrm{O}$ autor acredita que as pessoas agem de acordo com um conjunto de disposições práticas, chamadas por ele de habitus, relacionadas ao grupo social em que ele está inserido.

Desta forma, para se compreender essas relações objetivas, irredutíveis às interações, Bourdieu afirma que estas estão relacionadas à posição que as pessoas ocupam na divisão dos recursos sociais. Estes recursos são divididos em três: i) Capital econômico: consiste nos bens de valor comercial, como a moeda, e os serviços que este capital pode providenciar; ii) Capital social: está relacionado à rede de relacionamentos que o indivíduo e a sua família possuem; iii) Capital cultural: além dos títulos escolares, todo tipo de qualidade, habilidade ou conhecimento que possuem, a capacidade de diferenciar socialmente as pessoas, tal como o domínio da linguagem culta, Matemática, Ciências, informações políticas etc.

As estruturas de classe são formadas tendo como base a maneira com que as diferentes espécies de capital estão distribuídas na sociedade. São aspectos relevantes: i) a quantidade total de capitais, de quaisquer espécies, acumulado; ii) a quantidade relativa de capital acumulado em referência ao total, ou seja, o peso relativo que cada capital possui no volume total adquirido.

É sabido que o capital econômico se encontra dividido de maneira desigual na sociedade. O mesmo acontece com o capital cultural, e é justamente nessa manutenção que o sistema escolar contribui para a reprodução das classes.

Bourdieu afirma que a escola é um instrumento de manutenção das estruturas de 
classe e reprodução da cultura dominante, uma vez que os arbítrios culturais lecionados são escolhidos com base naquilo que a classe dominante acredita ser necessário, bem como é lecionado utilizando-se as normas da língua culta, o que demanda um domínio da língua materna, que nem sempre as classes médias e inferiores possuem acesso. Outro aspecto são as avaliações de estilo meritocrático, que excluem as classes médias e inferiores, com base nos conceitos já aprendidos pelas classes dominantes.

Bourdieu não questiona a questão moral e ética de professores preconceituosos e sua capacidade de prejudicar alunos de acordo com a sua classe social. $\mathrm{O}$ autor questiona quando os agentes do sistema de ensino utilizam de artifícios homogeneizantes e imparciais para avaliar indivíduos, com capitais adquiridos diferentes, pois é justamente na falta de conhecimento dos seus antepassados que a manutenção das classes e a reprodução da classe dominante acontecem.

Em seu trabalho sobre a Teoria do Sistema de Ensino, Bourdieu e Passeron (2009a), afirmam que sem um corpo profissional, ou seja, sem a racionalização e divisão do trabalho, não existe um ofício. Para eles, um corpo que exerce o trabalho pedagógico racionaliza a organização social, consagrando à instituição a sua autonomia.

Todo sistema de ensino é reprodutor de arbítrios culturais, sendo que nem sempre os produzem, i.e., os avanços científicos, a evolução dos sistemas de idiomas, sistemas de organização e autoridade etc; é nessa reprodução de arbítrios culturais que o sistema reproduz as relações de classes. Essa instituição é produtora de habitus escolar ${ }^{2}$, ao mesmo tempo em que não conhece a sua origem, nem as condições para sua reprodução. Para que a produção aconteça de maneira satisfatória, é necessário haver um corpo de agentes especializado e homogêneo, capaz de assim gerar habitus similares e duráveis.

De acordo com os autores, o processo de institucionalização da Pedagogia acontece em dois níveis. No primeiro, a ação pedagógica é não especializada e é levada a todos os membros da sociedade. No segundo, existe uma autoridade pedagógica, estabelecida por lei.

Um fato curioso, que é importante ressaltar, está relacionado à ignorância do sistema de ensino em enxergar que a violência simbólica (será aprofundado mais à frente) exercida tem relação com as forças de outros grupos ou classes. O sistema de ensino reforça a ilusão de neutralidade, uma vez que o professor é um reprodutor deste tipo de ideologia.

O chamado, hoje, de ensino tradicional é descrito por Bourdieu e Passeron (2009b) como uma cultura escolar rotinizada, homogeneizada e ritualizada. Para eles, os exercícios repetidores são considerados estereótipos na criação de habitus. Os professores tendem a reproduzir a maneira como eles foram ensinados, sustentando o sistema de ensino por meio da autorreprodução, ou seja, o mestre tende a imitar o seu próprio mestre. Desta forma, as transformações na cultura escolar são mais lentas em relação às outras esferas da cultura, uma vez que estão enraizadas em modelos antigos de ensino.

Para Bourdieu e Passeron (2009b), o trabalho pedagógico deve ser uma inculcação

\footnotetext{
${ }^{2} \mathrm{O}$ dito habitus escolar está ligado às disposições práticas que acontecem dentro do ambiente escolar.
} 
do habitus, uma vez que este se perpetua, mesmo quando a atividade educativa cessa, sendo capaz de perpetuar mais duravelmente uma atitude do que qualquer coerção política. Para eles, a Educação é um instrumento fundamental para a continuidade da história, e por isso tende a ser mera reprodutora de arbítrios sociais.

A eficácia do trabalho pedagógico está diretamente ligada à classe na qual está inserida. As pessoas que pertencem às classes mais baixas, embora igualmente capazes, são mais teimosas, pois a cultura dominante tende a achar que a cultura dominada é algo ilegítimo. Com isso, o ensino obrigatório se torna a evidência clara do domínio da cultura dominante sobre a dominada.

O trabalho pedagógico pode ser dividido em duas instâncias. A primeira, chamada de trabalho pedagógico primário, é feito pela família, que exerce influência irreversível no habitus, enraizando as suas características de classe. A segunda instância do trabalho pedagógico, chamada de trabalho pedagógico secundário, é oferecida pela escola, e depende do trabalho realizado pelo primeiro, sendo constituído como uma sequência deste.

Os autores trazem uma crítica às escolas, no que diz respeito a uma "ideologia da recusa", que consiste na negação de que existe uma história anterior a ela. Esta ideologia reforça o pensamento de que a instituição de ensino é um local neutro, e que todas as pessoas que ali ingressam possuem os mesmos acúmulos de capitais, em suas diversas espécies. Este pensamento propicia que a meritocracia entre em vigor nas escolas, reforçando, ainda mais, a reprodução das estruturas de classe.

A pedagogia implícita, presente no trabalho pedagógico primário, é mais eficaz para a transmissão de conhecimentos populares, indiferenciados e totais. Já no trabalho pedagógico secundário, a pedagogia ali presente é responsável pela produção explícita de habitus codificados e formais. "Um trabalho pedagógico é tanto mais tradicional quanto menos claramente delimitado como prática específica e autônoma e quando a instituição responsável pelo seu exercício é mais total ${ }^{3}$ e indiferenciada" (BOURDIEU; PASSERON, 2009b, p. 11).

Para exemplificar esta relação, a comunicação, em um trabalho pedagógico tradicional, entre o professor e o aluno é feita de maneira unilateral, do professor para o aluno, como um "transmissor" e um "receptor".

A produtividade do trabalho pedagógico está relacionada com a proximidade que o secundário tem com o primário. Desta maneira, a ação pedagógica secundária tende a ser excludente, uma vez que delimita e prioriza os seus destinatários legítimos. Assim, a função do trabalho pedagógico secundário é a de eliminação sob a forma dissimulada de seleção.

Toda atividade pedagógica produz uma autoridade pedagógica, na qual está institucionalizado o poder de exercer a violência simbólica. Sem a autoridade pedagógica não é possível exercer a ação pedagógica, pois essa detém o direito sobre a imposição de significações.

As formas de legitimação da autoridade pedagógica variam ao longo da história, mas

\footnotetext{
3 Instituição total é um termo utilizado para denominar aquelas instituições que visam controlar as pessoas, substituindo as interações dos indivíduos por alternativas internas. Exemplos são: Prisão, Igreja, Exército.
} 
de acordo com Bourdieu e Passeron (2009b), a escola é a representação da legitimidade simbólica dessas autoridades, uma vez que enfatizam o papel destas, como mecanismo de reprodução social.

É importante salientar que a legitimidade da autoridade pedagógica deve ser reconhecida entre as partes e não deve se reduzir a processos comunicativos. "Se não houver reconhecimento da autoridade pedagógica não há reconhecimento da legitimidade do emissor, logo não há aprendizagem" (BOURDIEU; PASSERON, 2009b, p. 8).

Porém, a autoridade pedagógica é sempre fruto de uma delegação de autoridade, ou seja, a instância que conseguir impor a sua cultura perante os outros, controlará o monopólio cultural dominante. Como consequência, o direito de violência simbólica concedido a uma autoridade pedagógica é sempre limitado, também chamado de princípio de limitação de autonomia.

A violência simbólica consiste no poder de inculcar significações como legítimas por meio das relações de forças dissimuladas, que existem entre as relações. Desta forma, toda ação pedagógica é uma violência simbólica, uma vez que existe uma relação de força entre as partes (autoridade pedagógica e aluno), à qual será imposta uma significação arbitrária.

As relações de força presentes na ação pedagógica são dependentes das relações de força presentes na estrutura social. Assim, a ação pedagógica reproduz a cultura dominante, reproduzindo, também, as relações de poder de determinado grupo social.

Devemos salientar que os conceitos de inculcação (ato de sugerir significações derivadas de um princípio universal) e imposição (poder arbitrário) são conceitos presentes na ação pedagógica, mas não na comunicação, pois esta pressupõe que exista igualdade entre os interlocutores. Esta ideia nos permite concluir como é errôneo o pensamento de que numa ação pedagógica exista uma verdadeira relação de comunicação, entre quem a exerce e quem está sob sua influência.

A partir dessa ideia, podemos perceber como os arbítrios culturais escolhidos de maneira arbitrária (de modo a realizar a manutenção das classes) mantêm a sua posição de dominância. Esta situação origina a chamada ação pedagógica dominante, que impõe valores e significações à ação pedagógica dominada.

A ação pedagógica é sempre considerada uma violência simbólica, pois tem como objetivo impor e inculturar certas significações selecionadas, enquanto outras são deixadas de lado. Esta seleção é feita por grupos ou classes dominantes de maneira aleatória. Deve-se notar, no entanto, que, em Bourdieu e Passeron, há uma abertura com relação à ideia de mudar esse estado de coisas e a possibilidade de pensar "um ensino realmente democrático", apoiado por "uma pedagogia realmente racional", isto é, uma pedagogia que, em vez de estar implícita como a atual dominante, seria uma pedagogia com o objetivo explícito de "neutralizar [...], de uma escola infantil à universidade, a ação de fatores sociais da desigualdade cultural" (BOURDIEU; PASSERON, 1964, p. 114-115). Certamente não é fácil de imaginar o conteúdo dessa chamada "pedagogia racional, baseada em uma sociologia das desigualdades cultu- 
rais", mas a ideia de sua possibilidade - dentro do referencial teórico que nós escolhemos permite-nos conceber uma visão menos pessimista e, com base nos resultados relativos ao abandono do curso de Física apresentados neste artigo, nutrir uma esperança de melhoria da situação, graças a um apelo ao esforço reflexivo dos professores.

Assim sendo, podemos concluir que a ação pedagógica tradicional, não crítica ou reflexiva, tem a função de reproduzir de forma mediada os interesses dos grupos dominantes, como veremos no decorrer deste artigo, nas relações de força existentes entre os cursos de Bacharelado e Licenciatura em Física da Universidade Federal de Ouro Preto.

\section{Encaminhamentos metodológicos}

A fim de iniciar nossos levantamentos de dados para o desenvolvimento da pesquisa, elaboramos dois roteiros de entrevista, um que seria utilizado para interpelar os estudantes e o outro para os questionamentos aos professores, durante o processo de entrevista, que seria gravado em áudio e vídeo (para posterior transcrição e interpretação). Detalhes a respeito das questões pertencentes aos roteiros serão apresentados na próxima seção.

Cabe informar que a pesquisa seguiu todos os requisitos, no que se refere à questão ética. Todos os entrevistados assinaram um termo, autorizando os autores a utilizarem os dados aqui contidos. Para manter o sigilo das pessoas envolvidas, utilizamos nomes fantasias.

Sobre os alunos entrevistados, procuramos selecioná-los de maneira a conhecer a visão de alunos em diferentes épocas do curso. Assim, escolhemos, tanto da Licenciatura quanto do Bacharelado, um aluno do primeiro período (um calouro), um aluno que estava na metade do curso e um que estava prestes a se formar. Mais especificamente com relação aos cursos eles encontravam-se: 1 (um) do primeiro período, 1 (um) do terceiro período e 1 (um) do oitavo período, tanto para a Licenciatura quanto para o Bacharelado.

Dos seis alunos entrevistados, apenas uma aluna foi ouvida, visto que o número de mulheres no curso era significativamente inferior ao de homens, como observamos em momento anterior neste artigo.

Destacamos ainda que nenhum dos alunos entrevistados, exceto os dois calouros, estavam "ideais" no curso, ou seja, haviam sido aprovados em todas as disciplinas previstas para o semestre em que se encontravam. Porém, com o decorrer da pesquisa, constatamos que os calouros também sofreram com a reprovação em algumas disciplinas, totalizando um total de $100 \%$ de alunos em retenção, em ao menos uma disciplina.

Os cinco professores entrevistados foram selecionados de acordo com sua formação e a afinidade que possuíam com cada uma das habilitações. Também foi levado em consideração o tempo que os docentes lecionavam na Instituição, sempre elegendo um com maior tempo de casa e um contratado há pouco tempo. Desta forma, os eleitos foram dois professores 
com formação em Ensino de Física e três com formação em Física $\mathrm{Hard}^{4}$, sendo que esse terceiro foi selecionado por ser uma mulher e por atuar nas duas habilitações.

As entrevistas foram realizadas, todas na Sala de Pesquisa em Ensino de Física, e duraram em média de 30 minutos por entrevista e ocorreram nos meses de junho e julho de 2017.

Apesar de a pesquisa apresentar os dados de um estudo de caso, pensamos que podemos estendê-la a outros contextos, uma vez que a baixa terminalidade do curso de Física, aliada à alta taxa de evasão, está presente em outras Instituições de Ensino Superior, como já mencionado anteriormente.

\section{Os dados e algumas interpretações iniciais}

As entrevistas foram assistidas com o intuito de identificar possíveis pontos que pudessem ser semelhantes nas falas dos alunos e dos professores. Justificamos que a completude dos dados não foi inserida neste artigo, em função da limitação de páginas para sua elaboração, contudo foram consideradas as análises de todos eles para as considerações conclusivas que puderem ser evidenciadas.

A pesquisa foi feita de maneira a se evitar apenas perguntas e respostas, sendo assim procurou-se manter um ambiente agradável e reflexivo, para que os entrevistados se sentissem estimulados a manifestarem suas percepções a respeito do fenômeno em estudo.

Primeiramente trouxemos os dados dos estudantes e na sequência os dos professores.

\section{V.1 Considerando os relatos dos alunos}

Inicialmente, organizamos as informações relatadas a respeito da "história que os estudantes contavam sobre sua vida até a matrícula no curso atual" - pois este era o foco da nossa primeira questão do roteiro elaborado.

Pudemos perceber que, dentre os seis alunos entrevistados, quatro começaram a falar da sua história a partir das suas experiências no Ensino Fundamental. Os que não iniciaram com essas argumentações, utilizaram a mesma frase: "Eu sempre gostei de Física" e, logo em seguida, voltaram para as experiências escolares.

Tendo em vista as respostas dos alunos pudemos dar início à um delineamento do perfil dos alunos do curso de Física, e com isso percebemos que todos, em algum momento, passaram pela escola pública. Dentre os seis alunos entrevistados, nenhum deles cursou toda a sua Educação de base em escolas particulares. No entanto, três deles fizeram essa etapa da sua formação, de maneira integral, em escolas públicas. Dos três alunos que passaram pelas escolas particulares, um o fez durante o Ensino Fundamental, enquanto os outros dois no Ensino

\footnotetext{
${ }^{4}$ Física Hard, ou Física Dura é denominado aqui para referenciar a área da pesquisa em Física, em que se estudam apenas os fenômenos da natureza, de maneira segregada dos fenômenos sociais e políticos, que fomentam a própria pesquisa e circundam a sociedade ao seu redor.
} 
Médio. Também observamos que dois alunos, além de cursarem o Ensino Médio em escolas públicas, o fizeram em escolas de ensino técnico.

Em seguida, questionamos os estudantes sobre sua situação no curso em que estavam matriculados. Usamos a denominação "ideal" que representaria, segundo nossos esclarecimentos a eles, estar aprovado em todas as disciplinas previstas para o período em que se encontravam.

Pudemos perceber que apenas dois alunos estavam ideais no momento da entrevista, e que eram os calouros (aqueles entre 0 e 1 ano de curso). Após as entrevistas, em conversas paralelas, foi constatado que nenhum dos dois encontrava-se em situação ideal, ou seja, mesmo sem o término do ano letivo já ficara constatado que estariam retidos em alguma disciplina do primeiro ano. Fato que alonga o tempo de conclusão do curso.

Nossa terceira questão considerou as "oportunidades existentes dentro da Universidade relativas ao curso em que estava matriculado".

De todas as falas, conseguimos identificar que dois alunos reconheciam que existiam oportunidades no curso. Porém, estas oportunidades eram amplamente dificultadas, pela complexidade em se manter o coeficiente acima de 6.0. A Física tinha um amplo histórico de poucas pessoas conseguirem manter a sua média satisfatória, e de acordo com os editais para programas de pesquisa e/ou extensão, esta nota era obrigatória. Assim, muitos alunos, que possuíam potencial para participar de um projeto, eram excluídos antes mesmo de tentarem o processo seletivo. Ilustramos essa afirmação com a transcrição de um dos depoimentos coletados:

Quem tem (coeficiente), geralmente já tem bolsa, e ai a gente vê as bolsas de Iniciação Científica ou de pesquisa, extensão que são do curso indo para outros (Engenharias), porque a gente não consegue suprir essa demanda. (Bárbara)

Outro fator que dificultava as oportunidades no curso, de acordo com 2 alunos da Licenciatura, era a existência de poucos professores da área para oferecerem projetos de iniciação científica, ou extensão. De um corpo docente de 34 professores, apenas 4 deles possuíam formação pós-gradual em Educação, o que representava aproximadamente 12\%. Desses 4, apenas dois ofereciam projetos de pesquisa na área. Novamente inserimos um exemplo do que foi comentado:

São quatro que estão trabalhando realmente nessa área. Os outros tão desenvolvendo pesquisa que nós não conseguimos entrar ou, tipo, (não acréscimo nosso) nos agrada muito. (Leandro)

Os alunos do Bacharelado, por outro lado, comentaram que os professores dessa área estavam concentrados em áreas muito específicas. As oportunidades para trabalhar com outras áreas, senão aquelas em que os professores tinham um contato amplo eram, geralmente, negadas, fato que os obrigavam a procurar orientações fora da Universidade ou sucumbir às ênfa- 
ses já existentes. Inserimos dois relatos a respeito dessas considerações:

Hoje eu acho que elas são muito restritas. Ou você é Físico Geral ou é Materiais. (Henrique)

Eu, sinceramente, acho que falta um pouco de, como eu vou dizer... outras áreas para trabalhar, sabe? Eu acho que aqui o foco é muito em material. (Saulo)

Percebe-se que as oportunidades existiam para ambas as habilitações, no entanto, elas eram restritas às classes ditas elitizadas, ou seja, àqueles que possuíam coeficiente (média geral superior ou igual a 6,0) e pertenciam ao grupo dominante do Departamento.

Alguns alunos relataram também a falta de perspectiva para o mercado de trabalho, quando entraram no curso. Para tentar contornar esse problema, foi sugerido que os professores saíssem com os alunos em visitas técnicas para conhecerem locais de trabalho, em que um físico poderia atuar, além da escola; e, também, sugerir a participação dos estudantes em congressos e semanas de estudos, situações em que ocorreria a promoção e a disseminação do conhecimento e das áreas de atuação do profissional.

A próxima questão abordada diz respeito especificamente à escolha realizada pelo estudante entre a Licenciatura e o Bacharelado e como ele percebia esta situação entre os cursos do ponto de vista dos professores e dos próprios alunos.

Após a análise, pudemos constatar a variância nos relatos que vão desde a cobrança maior para com os alunos da Licenciatura até a não verificação dessa diferença na exigência por parte dos professores. Também ficou perceptível que há um discurso social geral que se repetiu com esses depoentes, quando alguns disseram "que os estudantes do curso de Bacharelado são mais preparados do que os alunos da Licenciatura". E, ainda houve uma complementação argumentativa "o curso de Licenciatura é mais fácil que o de Bacharelado [...], por ter mais disciplinas de Física teórica, isto dificultaria o curso, enquanto na Licenciatura é só ler textos e fazer uns trabalhinhos".

As piadas que circundam os alunos podem, também, ser um elemento que potencializa a evasão do curso de Física. Um dos alunos relatou que existem muitas piadas com quem estuda Física, entre elas: "Você vai morrer de fome"; "Rato de laboratório, que vai viver dentro do laboratório fazendo pesquisa", em geral elas eram manifestações de estudantes de outro curso, que não da Física.

Por fim, a última questão que fizemos abordava diretamente a opção por abandonar o curso e a relação desta atitude com o posicionamento dos professores.

Todos os alunos, inclusive os calouros, responderam que, de certa maneira, os professores podiam ter alguma influência neste processo, e para justificar suas percepções utilizaram palavras ou expressões como: arrogância, desmoralização, piadas de mau gosto.

Eles também destacaram a "inflexibilidade na hora da correção das provas e trabalhos", evidenciando um problema recorrente no ensino tradicional, que perpassa a unicidade 
do saber, ou seja, apenas aquilo que o professor dizia estava correto.

Além desses comentários, temos ainda outras problemáticas evidenciadas que perpassam por frustrações pessoais como: o excesso de reprovações que não estavam presentes na Educação Básica e que agora ocorria, a forma única de ensinar do docente.

Como comentado anteriormente, nossa intenção foi a de dar voz a estudantes e a docentes, para podermos tecer algumas compreensões a respeito destes fenômenos: evasão e retenção nas habilitações do curso de Física da instituição em que atuamos profissionalmente. Segue, então, a organização de diversas informações coletadas junto aos professores, assim como para os alunos. Não tivemos como trazer a totalidade delas, todavia todos os pareceres foram considerados no processo analítico.

\section{V.2 Considerando os relatos dos professores}

Assim como com os alunos, iniciamos as entrevistas com uma pergunta de contexto geral, para que pudéssemos identificar um perfil dos professores selecionados.

Pudemos perceber que o foco trazido para discussão pelos professores foi diferente dos comentários dos alunos. Enquanto os alunos relataram a respeito de sua vida acadêmica, os professores não comentaram tanto, atendo-se mais às suas vidas pessoais. Apesar dessa divergência nos momentos iniciais das entrevistas, houve semelhanças argumentativas, entre as quais destacamos: dois docentes declararam o envolvimento com movimentos sociais durante o seu período formativo, considerando que isso foi fundamental para a determinação dos seus planos futuros; dois deles sentiram a necessidade de trabalhar, enquanto estudavam para se manter na Universidade; situações essas também levantadas pelos estudantes, quando entrevistados.

Um fato relatado por 3 docentes nos chamou a atenção: pouco contato prévio com a docência. Complementando que ao buscarem as Instituições de Ensino Superior para trabalharem pensavam primariamente em "um refúgio para realizarem as suas pesquisas", todavia "acabaram tendo que dar aulas".

Após esse preâmbulo, questionamos os professores como eles justificavam a quantidade tão baixa de egressos dos cursos de Licenciatura e Bacharelado em Física em que atuavam como docentes. Diversos fatores foram indicados apenas uma vez e somente um deles foi recorrente para 3 depoentes - "sedução de outros cursos".

Tal "sedução" foi justificada por meio de argumentações complementares como: "promessas de oferta de emprego"; "qualidade de vida"; "valorização social".

Ainda foram levantadas algumas problemáticas gerais, como: problemas internos da Universidade; a forma de vida instaurada no município e que foi adjetivada por "opressora", quando da necessidade de os estudantes morarem em repúblicas e não possuírem um ambiente adequado para uma rotina de estudos, pois neste caso específico há, nas repúblicas, algumas "obrigações" que os moradores precisam cumprir para se manterem nelas (ir a festas corriqueiramente, manter contato social com as outras repúblicas etc.). Hábitos esses que geram 
um alto índice de reprovações, desmotivando o estudante e levando-o à evasão ou à retenção alongada no curso.

Por fim, os professores foram interpelados a respeito dos ingressantes dos cursos de Física da Universidade. Dentre as manifestações analisadas, somente um aspecto foi recorrente em duas falas: "a intenção prévia de mudar de curso", ou seja, de fazer do curso de Física "um trampolim para as Engenharias".

Após esses encaminhamentos interpretativos dos relatos apresentados pelos estudantes e pelos docentes durante as entrevistas, retomamos as nossas questões que deflagraram o desenvolvimento desta investigação: quais seriam os motivos que estariam levando os alunos dos cursos de Licenciatura e Bacharelado em Física de nossa Instituição a evadirem ou ficarem retidos?

\section{Retomando os dados}

Com base nos dados coletados nas entrevistas, especialmente na primeira pergunta, foi possível concluir que todos os alunos entrevistados passaram, em algum momento, pela escola pública e que a maior parte deles é de classe média ou inferior. Com exceção de alguns poucos alunos, que realmente escolheram fazer Física, os alunos que se matriculam são, em geral, aqueles que não conseguiram entrar em cursos de prestígio, ou de elite, como as Engenharias, o Direito ou a Medicina.

Bourdieu (1998) faz uma análise sobre o destino que as crianças das diversas classes sociais possuem. Para ele, a atitude que leva os pais a decidirem o destino de seus filhos está relacionada com a contínua lembrança dos êxitos parciais das crianças de seu meio, ou seja, a escolha também está relacionada com a interiorização do destino, previamente determinado para a sua classe social.

Para explicar os motivos que levam à renúncia dos pais em enviar os filhos a estabelecimentos de ensino secundários, Bourdieu (1998) fala que o desejo razoável de ascensão social só pode existir quando as chances reais de êxito forem substanciais para satisfazer suas expectativas. Ainda mais, diz que isso acontece, pois ao conseguir êxito a tendência é elevar o seu nível de aspiração. No entanto, aquele que fracassa pode ter duas reações distintas: "situar o seu alvo muito baixo, frequentemente aquém de seu êxito passado (...), ou então ele situa seu alvo acima de suas possibilidades" (LEWIN, 1948 apud BOURDIEU, 1998b, p.10).

De acordo com Bourdieu (2009b), a escola é um mecanismo de manutenção das estruturas de classe, uma vez que como os arbítrios culturais lecionados nelas são escolhidos arbitrariamente e, seguindo a lógica dominante, as classes inferiores não possuem acesso a eles, e por isso a dificuldade em entrar em cursos de maior status é maior. A meritocracia que é implementada dentro da escola nas atividades de ensino e avaliação, transforma o exame principal instrumento de ascensão escolar - no principal instrumento de exclusão social.

Outro motivo de acreditarmos ser a escola um mecanismo de manutenção das estruturas de classe é o fato, de maneira geral, de as escolas públicas brasileiras terem uma infraes- 
trutura ruim. Segundo o relato dos alunos entrevistados, isso foi o que os impediu ou dificultou o acesso ao conhecimento, seja porque os professores não possuíam as devidas condições para ensiná-los, seja porque a escola não era um ambiente onde eles gostavam de estar.

O cenário na UFOP não é tão diferente, embora a infraestrutura seja significativamente superior, conflitos com colegas e professores também existem. Quando perguntamos aos alunos sobre as oportunidades existentes no curso de Física, eles nos responderam que elas existem, mas não são para todos. Da mesma forma, que o exame é um mecanismo excludente, antes de o aluno entrar na Universidade, durante o período que ele está estudando, o coeficiente é uma das suas maiores preocupações.

De acordo com o regimento da Instituição, a média mínima necessária para a aprovação nas disciplinas é de 60\%, ou 6,0. Seguindo essa prerrogativa, os alunos que desejam pleitear uma bolsa de Iniciação Científica, ou outros projetos de pesquisa, devem possuir um coeficiente geral de no mínimo 6,0. Como vimos na segunda pergunta, apenas 2 alunos estavam ideais, no momento das entrevistas, o que já não era mais verdade após o final do primeiro período, no qual todos haviam sido reprovados, em ao menos uma disciplina.

Este fato nos mostra como é difícil para os alunos manterem o ritmo de estudos, bem como o coeficiente mínimo necessário para, ao menos, tentar concorrer às bolsas. Algumas alternativas já foram sugeridas em Assembleias Departamentais, como enviar uma carta à Pró-Reitoria de Pesquisa e Pós-Graduação, solicitando uma mudança nos editais, para que os alunos possam concorrer às bolsas, sem estarem vinculados aos coeficientes. Assim, a ideia seria modificar os critérios meritocráticos adotados para uma avaliação específica de cada aluno, que poderia levar em conta a motivação e a capacidade do aluno em permanecer em tal projeto.

Ambas as modalidades estão alocadas no mesmo Departamento, o que acarreta uma divergência de ideias. Elas, em geral, acontecem de maneiras ofensivas. Nas entrevistas, pudemos perceber a ocorrência de piadas do Bacharelado em relação à Licenciatura, tanto por parte dos alunos quanto dos professores. Piadas do tipo "Licenciatura é fácil", "Para ser Físico de verdade tem que ver Física", “Como assim vocês não têm EDO?”, reforçam a estrutura de classes presente na Universidade. Dentro desta estrutura, o Bacharelado constitui a classe dominante, enquanto a Licenciatura é a dominada e tem que se sujeitar às normas e regras da classe dominante.

Outro aspecto relevante que pode ser evidenciado nessa relação de dominância é com respeito a um menosprezo implícito, por parte dos bacharéis ou futuros bacharelados, que acreditam que somente a sua área realiza pesquisas e a Licenciatura atua somente na área do ensino.

Esta relação de dominância implícita, associada à necessidade de se ter um coeficiente mínimo para o pleiteio de bolsas de pesquisa, favorece um cenário de competitividade entre os alunos. Não é incomum haver momentos de reunião extraclasse dos alunos de Física, em que alguns não participam por terem que estudar, negligenciando momentos de diversão e 
prazer.

Com esse isolamento, evidenciamos o que um professor e um aluno relataram: a falta de identidade e afinidade entre os alunos do curso de Física.

Os alunos não são unidos, não possuem o costume de fazer grupos de estudos, desde o início do curso. Somente aqueles que resistiram aos primeiros períodos percebem como isso é importante. Essa desunião contribui para não criar uma identidade do aluno de Física - independentemente da sua habilitação - o que propicia as piadas, já expostas, por parte dos outros cursos da UFOP.

Outra relação de dominância, inferida, foi expressa na relação entre professores e alunos. De acordo com estes, um dos principais fatores que levam à evasão é referente à superioridade, à arrogância e ao menosprezo, de alguns professores para com os alunos, dentro e/ou fora da sala de aula. Esta situação contribui para que os alunos sintam medo ou receio de expressar as suas ideias, quando não são as mesmas advindas dos professores, pois acreditam que podem sofrer algum tipo de perseguição em disciplinas futuras. Esse medo também pode ser evidenciado na falta de participação dos alunos, onde eles poderiam ser representados, como por exemplo, em órgãos colegiados e acabam por reforçar ainda mais essas relações de dominância.

\section{Considerações evidenciadas}

Como informado anteriormente, a investigação que desenvolvemos e cujos resultados trazemos neste artigo teve por objetivo identificar os principais motivos da evasão ou da retenção no curso pelos estudantes de Física da Universidade Federal de Ouro Preto. Para compreender tal fenômeno, realizamos algumas entrevistas com alunos e professores do curso em questão.

Pierre Bourdieu foi o referencial teórico que balizou nossas interpretações. Com maior especificidade, focamos nas considerações em que o autor apresenta um panorama sobre o surgimento e o desenvolvimento das estruturas de classe e sua Teoria relativa ao Sistema de Ensino.

Levando em conta o que Bourdieu assume e descreve, foi possível perceber como a estrutura no interior da UFOP é bastante complexa, e cremos que não o seja unicamente, as demais Universidades provavelmente também o são. Além disso, pudemos evidenciar algumas relações de dominância, naquele campo de pesquisa, entre elas destacamos: do Bacharelado sobre a Licenciatura, dos professores sobre os alunos, dos cursos ditos elitizados sobre os cursos de Ciência Básica, dos republicanos sobre os demais alunos. Delinear essas relações foi fundamental, para evidenciarmos as principais razões pelas quais os alunos evadiam ou ficavam retidos no curso. Como nós pudemos notar anteriormente, há em Bourdieu e Passeron alguns indícios de encorajamento para transformar as situações pedagógicas de dominação e de "violência simbólica" (BOURDIEU; PASSERON, 1964).

Diante dos nossos levantamentos, foi possível identificar que a evasão no curso de 
Física estava diretamente relacionada com a retenção dos alunos, ou seja, quanto mais tempo ficavam retidos mais aumentava a possibilidade de evadir. Isso nos levou a elaborar alguns motivos para tal fenômeno: os conflitos existentes entre professores e alunos dentro de sala de aula, associados à falta de empatia, à formação dos professores, bem como o desinteresse dos alunos. Tais situações, segundo nossas ponderações, podem ser vistas como mais um dos fatores que contribuíam para a manutenção das estruturas de classe dentro da Universidade, uma vez que os alunos eram dominados pelos professores, e muitas vezes pelo medo não encontravam espaço para dialogar com eles.

Outro problema destacado pelos alunos da Licenciatura diz respeito ao número de professores contratados na área, bem como à falta de disciplinas eletivas oferecidas por eles disciplinas de caráter optativo, em que o aluno pudesse decidir quando e qual cursaria - para complementação do currículo, além da disponibilidade de poucos projetos de pesquisa nessa área. Naquela ocasião, o Departamento contava com aproximadamente $10 \%$ do corpo docente com formação em Ensino de Física, e uma demanda de reformulação da Licenciatura, com 3200 horas, proposta pelo MEC, seria, sem dúvida, necessária a contratação de mais professores.

Acreditamos que uma das maneiras para se evitar ou diminuir a evasão no curso de Física em estudo, está na necessidade de se desestabilizar essas relações de dominância supracitadas. Para isso, é necessário que exista um diálogo entre docentes e discentes, momento em que eles poderiam expor seus pontos de vista e negociarem a melhor solução para os problemas existentes.

Outro ponto que podemos destacar e que contribuiria para minimizar a retenção, e, por conseguinte, a evasão, seria a flexibilização de burocracias para a participação em grupos de pesquisa, sejam eles de Iniciação Científica, projetos de extensão, Programa de Educação Tutorial (PET) ou outros. Tanto os alunos quanto os professores relataram que existiam oportunidades no curso, mas apontavam, também, as barreiras que excluíam aqueles que possuíam interesse, mas não satisfaziam os critérios do sistema.

Destacamos, porém, que alguns estudos sobre os fatores que influenciam a permanência, bem como a desistência dos alunos no curso de Física continuam a ser realizados (CARVALHO; UENO-GUIMARAES, 2019a; CARVALHO; UENO-GUIMARAES, 2019b). Além destes estudos, um esforço tem sido feito por parte dos colegiados, no acolhimento dos alunos, quando chegam à Universidade. Diversos programas de ajuda, como monitorias e aulas extracurriculares ministradas pelo Programa de Educação Tutorial são amplamente divulgadas e recorrentes. Outros exemplos de ajuda, que podem ser encontrados na UFOP, são os projetos que a Pró-reitoria de Assuntos Comunitários e Estudantis e Pró-reitoria de Graduação, que são órgãos da comunidade acadêmica da Universidade, auxiliam e tentam ajudar a condição de permanência do estudante, com bolsas de apoio financeiro e projetos, para o bem-estar pessoal como o Projeto Caminhar oferece.

Da mesma forma, os alunos do Bacharelado criticavam o número reduzido de áreas 
de formação dos professores efetivos e temporários. Como a habilitação oferecia duas ênfases: Física de Materiais ou Física Geral, eles se viam obrigados a realizar projetos em uma delas, ou seja, julgavam que as opções eram limitadas e que não consideravam as habilidades ou necessidades dos estudantes.

Os professores citaram diversos motivos para o baixo número de egressos, mas não destacaram os mesmos problemas que os alunos. Para os primeiros, era um problema de sedução dos outros cursos, em especial, das Engenharias, e a vida universitária, na cidade em questão, também não contribuía para a dedicação necessária aos estudos. Para os segundos, existia um problema relacionado aos professores, associado à falta de perspectivas no mercado de trabalho. Fatos que nos levam a considerar que: enquanto houver essa divergência, o curso de Física pesquisado permanecerá com um alto índice de evasão e retenção.

Entendemos que o número de alunos e professores entrevistados é insuficiente para se fazer uma generalização do estudo para outras universidades, porém acreditamos que este artigo traz apontamentos contundentes para a discussão do assunto, tanto na UFOP, quanto em outras. Além disso, o resultado da investigação aponta iniciativas que podem minimizar tais índices.

\section{Referências}

ABRAMOVAY, M.; CASTRO, M. G. Ensino médio: múltiplas vozes. Brasília: MEC, 2003.

ALMEIDA, J. B.; SCHIMIGUEL, J. Avaliação sobre as causas da evasão escolar no ensino superior: estudo de caso no curso de licenciatura em Física no Instituto Federal do Maranhão. REnCiMa, São Paulo, v. 2, n. 167, p. 167-178, 2011.

BAGGI, C. A. S.; LOPES, D. A. Evasão e avaliação institucional no ensino superior: uma discussão bibliográfica. Avaliação, Campinas; Sorocaba, v. 16, n. 2, p. 355-374, 2011.

BARROSO M. F.; FALCÃO, E. B. M. Evasão universitária: o caso do Instituto de Física da UFRJ. In: ENCONTRO NACIONAL DE PESQUISA EM ENSINO DE FÍSICA, 9, 2004, Jaboticatubas. Anais [...], Jaboticatubas: Sociedade Brasileira de Física, 2004. p. 1-14.

BOURDIEU, P. A Escola Conservadora: as desigualdades frente à escola e à cultura. In: NOGUEIRA, M. A.; CATANI, A. (org.). Escritos da Educação. Petrópolis: Vozes, 1998. p. 229-237.

BOURDIEU, P. Coisas ditas. São Paulo: Brasiliense, 2004.

BOURDIEU P.; PASSERON, J. C. Les Héritiers. Les étudiants et la culture. Paris: Les Editions de Minuit, 1964. 
BOURDIEU, P.; PASSERON, J. C. A reprodução: elementos para uma Teoria do Sistema de Ensino. 2. ed. Petrópolis: Vozes, 2009a.

BOURDIEU, P.; PASSERON, J. C. A reprodução: elementos para uma Teoria do Sistema de Ensino. Recensão de Ana Paula Rosendo. Covilhã: LusoSofia, 2009b.

CARVAlHO, G. L.; UENO-GUIMARAES, M. H. Fatores que influenciam a desistência/permanência de estudantes da graduação em Física. In: ENCONTRO DE SABERES, 2019a, Universidade Federal de Ouro Preto.

CARVALHO, G. L.; UENO-GUIMARAES, M. H. O processo de evasão no curso de graduação em Física: aspectos influenciadores. LEPSI, 13, 2019b, Universidade Federal de Ouro Preto.

FERREIRA, J. M. Um olhar sobre a evasão no curso Licenciatura em Física da Universidade Estadual do Centro-Oeste. 55f. 2017. Trabalho de Conclusão de Curso - Departamento de Física da Universidade Estadual do Centro-Oeste, Guarapuava.

HOLANDA, T. Estudantes da Ufop bebem mais que alunos de todas federais no Brasil. Estado de Minas, 2012. Disponível em:

$<$ https://www.em.com.br/app/noticia/gerais/2012/10/29/interna_gerais,326118/estudantes-daufop-bebem-mais-que-alunos-de-todas-federais-no-brasil.shtml>. Acesso em: 28 jan. 2020.

LIMA JÚNIOR, P.; OSTERMANN, F.; REZENDE, F. Análise dos condicionantes sociais da evasão e retenção em cursos de graduação em Física à luz da sociologia de Bourdieu. Revista Brasileira de Pesquisa em Educação em Ciências, v. 12, n. 1, p. 37-60, 2012.

RABELO, L. O. A evasão de alunos do curso de Física do Campus de Guaratinguetá da UNESP. 54f. 2012. Trabalho de Conclusão de Curso - Faculdade de Engenharia de Guaratinguetá da Universidade Estadual Paulista Julio de Mesquita Filho, Guaratinguetá.

SILVA, M. B. S.; FRANCO, V. S. Um estudo sobre a evasão no curso de Física da Universidade Estadual de Maringá: modalidade presencial versus modalidade à distância. Revista Brasileira de Aprendizagem Aberta e à Distância, São Paulo, v. 13, 2014.

SILVA FILHO, R. L. L.; MONTEJUNAS, P. R.; HIPÓLITO, O.; LOBO, M. B. de C. M. A evasão no ensino superior brasileiro. Caderno de Pesquisa, São Paulo, v. 37, n. 132, p. 641659, dec. 2007. Doi: http://dx.doi.org/10.1590/S0100-15742007000300007. 
SOARES, M. M. A evasão nos cursos de Licenciatura em Física: uma breve revisão bibliográfica. 22f. 2014. Trabalho de Conclusão de Curso - Universidade Estadual da Paraíba, João Pessoa.

UENO, M. H. A “tensão essencial” na formação do professor de Física: entre o pensamento convergente e o pensamento divergente. 156f. 2004. Dissertação (Mestrado em Ensino de Ciências e Educação Matemática) - Departamento de Física, Universidade Estadual de Londrina, Londrina.

UENO-GUIMARÃES, M. H. A escolha pela Física: gosto ou desafio? Saarbrücken: Ed. Novas Edições Acadêmicas, 2014. 